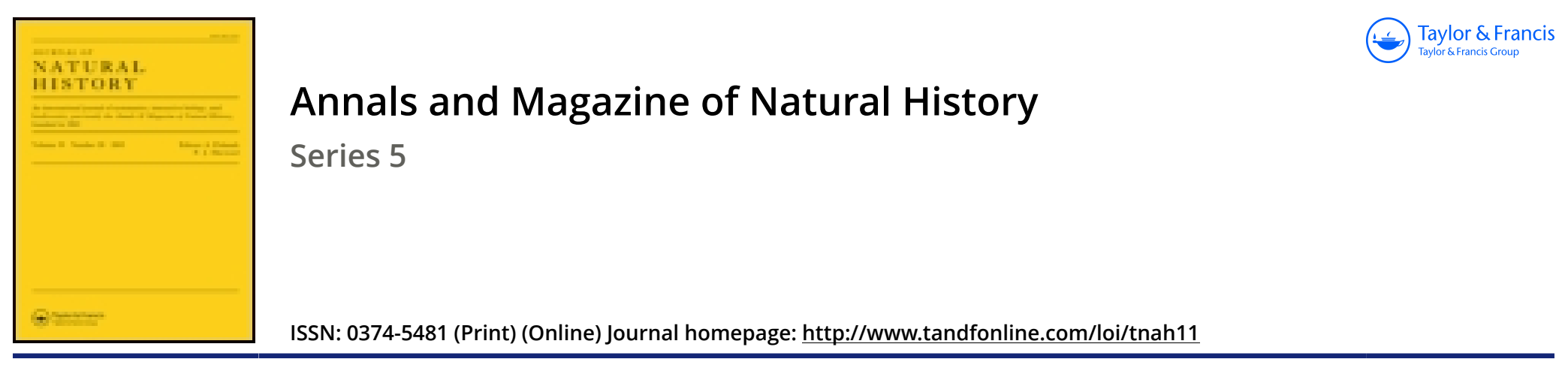

\title{
V.-Endogenous as distinct from exogenous division in the Amœban Rhizopods
}

\section{Surgeon-Major Wallich M.D.}

To cite this article: Surgeon-Major Wallich M.D. (1886) V.-Endogenous as distinct from exogenous division in the Amœban Rhizopods, Annals and Magazine of Natural History, 18:103, 30-34, DOI: 10.1080/00222938609459930

To link to this article: http://dx.doi.org/10.1080/00222938609459930

$$
\text { Published online: } 07 \text { Oct } 2009 .
$$

Submit your article to this journal $\sqsubset$

Џ Article views: 1 
The view which I believe to be the true one is that the remote ancestor of the hydromedusæ was a solitary swimming hydra or actinula, with no medusa-stage, but probably with the power to multiply by budding. I believe that this pelagic animal gradually became more and more highly organized and more perfectly adapted for a swimming life, until it finally became converted into a medusa with swimming-bell and sense-organs, developing directly from the egg without alternation, but exhibiting during its growth the stages through which it had passed during its evolution. After this stage of development had been reached, I believe that the larva derived some advantage from attachment to other bodies, either as a parasite within other medusæ or as what may perhaps be called a semi-parasite upon other floating bodies, such as the fronds of alga; and that it multiplied asexually in this sessile condition, giving rise to other larve like itself, all of which became medusæ.

I believe that the sessile or attached mode of life of the larva proved so advantageous to the species that it was perpetuated by natural selection, and that the primary larva then gradually lost its tendency to becorne a medusa, but remained a sessile larva, giving birth by budding to other larvæ which became sexual medusæ; that the medusa-characteristies of these secondary larvæ were accelerated, and that the primary larva gradually acquired at the same time the power to produce other larva, which remained permanently, like itself, in the hydra stage; that in this way the sessile hydra-communities with medusa-buds and free sexual medusæ were evolved; and that finally these communities became polymorphic, and that the sessile habit proved so advantageous that the free medusæ became degraded into medusa-buds or sexual buds on the bodies of the sessile hydras.

\section{V.-Endogenous as distinct from Exogenous Division in the Amoban Rhizopods. By Surgeon-Major WALLICH, M.D.}

I PROPOSE to show in this communication that whereas endogenous division in the naked Amœban Rhizopods is the prime factor in normal reproduction, exogenous division, in the majority of instances in which it is seen to take place during microscopic observation, is merely a mechanical disruption of the body-substance into two or more separate masses, produced accidentally by forces operating from 
without. In the former case it is a normal physiological process originating in an inherited idiosyncrasy of the organism, independently of any externally applied force; in the latter it is almost always a mere mechanical disruption of the animal's body-substance, brought about entirely by forces which are in nowise inherent in the organism. In short, endogenous division must be regarded as a normal function of the Amoeban structure, indispensable for the perpetuation of its kind; exogenous division being in reality an abnormal lesion of the structure calculated to interfere with the natural functions and development of the individual, just as it does in cases of injury accidentally inflicted on more highly organized creatures.

My attention having been lately redirected to this subject by the receipt of an important paper "On the Biology and Physiology of the Protozoa" * kindly sent me some months ago by Prof. Gruber, of the University of Freiburg (a translation of which, by Mr. W. S. Dallas, F.L.S., appeared in last month's issue of the 'Annals'), I am in hopes that the present observations may serve not only to confirm Dr. Gruber's views, but to furnish some new facts in relation to that portion of his paper which deals briefly but specially with "The Significance of the Nucleus in the Regeneration" of the Amoebse; the main portion of the paper being devoted to an exposition of the physiology of the Stentors. and other Infusoria proper.

But although I fully accept Dr. Gruber's conclusions concerning the paramount importance of the nucleus as a reproductive organ, and, as far back as 1865, showed my recognition of the fact by dividing the Rhizopods into three distinet orders based entirely on the absence or presence of the nucleus and contractile vesicle, I regret that I cannot accept the inference that division as noticeable in $A m c e b a$ when produced by artificial means, such as pressure or the dissecting-needle and ophthalmic scalpel, and when conducted under conditions so palpably unfavourable to the preservation of vitality in the detached masses of the Amoban body as imprisonment on an ordinary microscopical slide, can be regarded as affording a trustworthy parallel with what takes place when an accidentally-divided Amoeba is living in the midst of its natural habitat. Indeed it appears to me to be extremely doubtful if exogenous division, in my sense of the term, takes place at all under strictly normal conditions. When it occurs whilst the organism is under observation on a slide, it is only

* 'Berichte der naturforschenden Gesellschaft zu Freiburg i. B.' Band i. (1886) Heft 2. 
when the creature is subjected to undue pressure, or its movements are impeded by foreign matter, through which it has difficulty in forcing a passage. Whereas under perfectly natural conditions the creature is in all probability able either to push aside the obstructing matter or select another route. When closely confined between the glass slide and cover it has no such easy alternatives. Therefore all that can be safely inferred from watching the behaviour of an artificially or accidentally-divided and enucleate portion of an Amoeba is, that being endowed, in common with the rest of the body, with a diffused nervous faculty, this portion is, for some unknown reason, more detrimentally affected by the shock sustained by it than the remaining portion which possesses the nucleus.

Why the possession of the nucleus (which is never a permanently fixed organ in the Amcebe) should carry with it a superior degree of vitality, it is as yet impossible to say with any certainty. But, as first shown in my papers on "Amosba villos $a$ and other Indigenous Rhizopods," in the "Annals' for May and June 1863 (pp. 366, 436, and 437), and also in subsequent numbers of the same journal, there evidently subsists an intimate relation between the nucleus and the unique persistent area of the $A$ moban surface constituting its posterior region, whether this region be covered with any of the varieties of villons appendage or consist merely of a specially differentiated outer layer of sarcode-the intimacy of this relation becoming almost certain, firstly, from the specially differentiated area never undergoing Amobasis (as every other part of the sarcode body does) or taking part in the general pseudocyclosis; secondly, from the nucleus, after participation for a time in the general pseudocyclosis, almost always coming to rest in the vicinity of the area in question; and, thirdly, from the contractile vesicle, after participation temporarily in the pseudocyclosis, also coming to rest and generally discharging its contents close to the same region.

The extraordinary degree of vitality possessed by the posterior portion of $A$ moba is very signally manifest when lump after lump of the anterior portion is bitten off by some creature that preys on it, as, for instance, Coleps hirtus, or another Amoba with cannibal proclivities. Under these circumstances, if the nucleus and specially differentiated area remain intact, the original mass, although reduced to less than even half its normal bulk, will, in the course of an hour or so, move away as energetically as if no injury whatever had happened to it. Now this is precisely the condition of things existing when 
artificial division is effected by the scalpel or other mechanical means.

As regards spontaneously occurring division-that is to say, division effected by the mere contractility of the sarcode and without participation on the part of the nucleus-nothing is as yet known so far as I am aware. At the same time, I will not undertake to say that spontaneous division, in the sense indicated, may not occasionally take place under natural conditions. But even should spontaneous separation take place fifty times, or fifty times fifty, the process would not result in "regeneration," this being impossible unless the nucleus participates to such an extent as to apportion some share of the fecundative granules of which it consists to each separated fragment.

Nor have we any positive information as to whether a detached enucleate fragment of Amoba retains the faculty of digesting any food-material it may seize with its pseudopodia. But if negative evidence of a very powerful and constant kind is of any value, it is, I think, justifiable to assume that no detached enucleate portion of the Amœban body-substance can reproduce its kind in a perfect form, or multiply otherwise than by a repetition of purely unreproductive division.

Unfortunately our knowledge of the physiological functions belonging to these organisms must remain incomplete so long as the extraordinary difficulties inseparable from any strictly continuous examination of individual specimens from the beginning to the close of their entire life-cycle, under conditions not liable to interfere to any material extent with their free and healthy development, remain to be overcome. Th sse difficnlties, overcome as they nevertheless have been in the case of much more minute organisms than the Rhizopods, namely in the Monads, through the indefatigable perseverance and scientific skill of Messrs. Dallinger and Drysdale, are augmented rather than diminished in the case of the $A$ mobre, owing to the more protracted periods occupied by these organisms in passing through the various phases of their existence. For the present we must therefore rest content with collecting, piecemeal, all facts that bear upon the subject, and trust to the zeal of such competent observers as Dr. Gruber to work them out to their legitimate conclusions.

It now only remains for me to invite attention to a novel means of rendering the nucleus visible in the naked Rhizopods, and probably in the Protozoa generally, when the detection of this organ is rendered difficult, or even impossible, by bcing surrounded by more or less opaque particles of different kinds; the necessity for some more efficacious way of detectAnn. \& Mlag. N. Hist. Ser, 5. Vol. xvïi. 
ing its presence than has heretofore been employed becoming. obvious when, as shown by me in the case of Gromia (and as I believe will be found to be the case in every one of the naked Rhizopods which have hitherto been relegated to the lowest order of that group of organisms chiefly on account of being supposed to be deficient in this organ), it is almost certain that the error has arisen from the extreme difficulty, often encountered, of rendering the nucleus visible. The superiority of the method I am about to describe consists in its being simple, easy of application, and sure.

During some experimental trials I was making on the effect of a galvanic current passed through the water on slides containing living Amoboe and other organisms, which generally resulted in their being instantaneously killed without render. ing their internal organization more distinct than it was before, it occurred to one of my sons to try the effect of ordinary frictional electricity. The result proved most gratifying; for although, as in previous cases, the Amobce were instantly killed, their entire bodies were at the same time burst up, so to speak, into a homogeneous-looking mass of granular particles, the nucleus, however, in every instance forming a conspicuous object in the midst of these. So marked was this result that in some perfectly clean gatherings of Raphidiophrys elegans, so numerous that each field of the microscope was simply crowded with them, but in none of which a nucleus could be previously discerned, the instant the discharging knobs communicating with a single small Leyden jar were applied on opposite sides of the glass cover, and of course in contact with the water between the cover and slide, the effect I have described was produced in every one of them. The only precaution that has to be attended to is not to employ too powerful a discharge.

VI.-Descriptions of Sponges from the Neighbourhood of Port Phillip Heads, South Australia, continued. By H. J. Carter, F.R.S. \&c.

[Continued from vol, xvii. p. 516.]

Order VIII. CALCAREA (continued).

Observation.

Following Polejaeff's arrangement the Sycones will be inserted here, that is before the Leucones, as the radial chambers in the simplest and most typical forms, ex. gr. Grantia ciliata, Bk. (Sycandra ciliata, H.), appear to be closely allied 